\title{
The use of arrays in the learning of multiplication word problems in primary school
}

\section{Mayamiko Malola}

Department of Childhood Education, Faculty of Education, University of Johannesburg, South Africa.

Accepted 15 April, 2020

\begin{abstract}
The low performance of Grade 4 learners in the mathematical concept of word problems involving multiplication remains a concern for many researchers in mathematics education. Several studies conducted have largely focused on improving learners' performance on bare problems involving multiplication, with little focus on contextual problems. The small pilot study reported in this paper investigated the effectiveness of using arrays in improving learners' performance on contextual multiplication problems. A sample of six learners from a school in Soweto township (South Africa) was carefully selected to participate in the study. Tests, carefully designed lessons, and interviews were the major sources of data. The study found that arrays improved the overall performance of learners, and those who were initially identified as low performers showed greater improvement. The pilot study suggests that future research should focus on engaging a large sample of learners from township schools to ensure that the sample is more representative, and how teachers may be supported to use arrays when teaching contextual multiplication problems.
\end{abstract}

Keywords: Arrays, multiplication word problems, design research.

E-mail:mayamalola@gmail.com.

\section{INTRODUCTION}

Zhang et al. (2017) maintain that low mathematics achievement is a persistent challenge and multiplication word problem is a prominent area in which many learners experience difficulties. Through my own active involvement in the teaching of mathematics and observation of mentor teachers in different schools, I noticed that Grade 4 Learners struggle with solving word problems in general and those involving multiplication. There is literature (Csikos et al., 2012; Pfannenstiel et al., 2015; Thompson, 1999) demonstrating that multiplication word problems are a big challenge to learners in primary school and the consequences further manifest as they advance in their schooling career and in their daily life. Numerous studies (Barmby et al., 2009; Harries and Suggate, 2006) have also found that array representations enhance learners' understanding and solving of multiplication problems. However, a review of various studies suggests that the focus has largely been on using arrays to represent and solve multiplication problems involving bare calculations such as $5 \times 8$. This is an example of multiplication of whole numbers less than 10. Furthermore, curriculum documents reveal a focus on number sentence multiplication problems. Literature is lacking on the use of arrays to represent and solve multiplication word problems, an area that has emerged as of global concern. The growing concern accompanying the evidence of under-performance among primary school learners on multiplication word problems formed the basis for conducting this study.

\section{Research questions}

The pilot study sought to answer the following research questions: How do arrays influence the learning of multiplication word problems for Grade 4 learners? What is the Grade 4 learner's perception about the use of arrays to solve multiplication word problems? 


\section{Aims and objectives}

The aim of this pilot study was to explore the influence of arrays on Grade 4 learners' learning of multiplication word problems. Through a presentation of two lessons on multiplication word problems and array representations, followed by semi-structured interviews, this study explored how arrays influence the learning of multiplication word problems. I also investigated whether the learners found the use of arrays helpful in the learning of multiplication word problems. The results of the study are useful to inform a larger study involving a whole class or classes and working with teachers to use arrays as a support to solving multiplication word problems. The findings also make a small positive contribution to the challenge facing many learners when dealing with multiplication word problems.

\section{MATERIALS AND METHODS}

The methodology used for this study is design research. Design research is relevant for educational practice and policy as it aims to develop research-based solutions for complex problems in educational practice. Educational design research is the systematic study of designing, developing and evaluating educational interventions (Plomp and Nieveen, 2007). These interventions include educational programs, teaching-learning strategies and materials, products and systems as solutions for complex problems in educational practice. The research design also aims at advancing the researchers' knowledge about the characteristics of these interventions. The intervention that this study sought to design, develop and evaluate is the use of arrays in the teaching of multiplicative word problems.

\section{Sample selection}

In this research, the participants were six Grade 4 Learners from a class of 31 chosen through purposive sampling at a school situated in Soweto township. Purposive sampling was necessary to ensure that learners with different characteristics such as gender, high performers, average performers and low performers are equally represented in the study. Three boys and three girls were purposively chosen to ensure equal gender representation in the sample. To ensure equal representation of high, average and low performing learners in the sample, term one mathematics results list was used to choose one boy and one girl from the top third, middle third and lower third. Grade 4 was the best class for this research because it is the class where learners begin reading to learn. Grade 4 marks the transition from the lower primary where learners learn to read. Since the focus of this study was solving of contextual multiplication problems, it was necessary that participants should be able to read to learn.

\section{Data collection methods/tools}

Data was collected through pre-testing and post-testing, conducting a two lessons intervention with the six learners, participant observation, and semi-structured interviews.

\section{Participant observation and tests}

According to Taylor and Bagdan (1984), participant observation involves social interaction between the researcher and the subject. This allows the researcher to study first-hand experience and behaviour of subjects in situations. At some point the researcher may talk with the subjects about their experiences. In this study, I worked with Grade 4 Learners. I gave an assessment with a set of multiplication related word problems to solve both before and after the intervention. For example, Corin is putting out chairs in rows. He puts 4 chairs in each row. He has put out 4 rows. How many chairs does Carin put out? This is question 2 of 5 questions in the pre-test and question 5 out of 5 in the post-test. One question on the assessment sheet was an addition problem; Viren is packing books into boxes. He puts 5 books onto one box. He puts 6 books onto another box. How many books does Viren pack into the two boxes? This was not only necessary to allow learners to demonstrate their capacity to identify multiplication problems from a set of multiplication and addition problem, but also to deter the use of multiplication methods routinely in the assessment.

I gave learners the same assessment questions both before and after the intervention, with the question numbers changed in the post-test assessment. I presented two lessons to the six learners using materials drawn from Askew et al. (2017) study containing multiplication related word problems and how array representations could be used to solve such problems. Array is an arrangement of objects, pictures, or numbers in columns and rows, and is very important representations for multiplication ideas. The lessons incorporated all the six learners and ran for one hour each day. I observed, wrote notes and took pictures of how learners approached multiplication related contextual problems both before and after the intervention. By comparing the observational notes, and learners' performance on the assessment questions both before and after the intervention, I was able to get useful information to help answer the overarching research question of "how arrays influence the learning of multiplication word problems in grade 4? These observational notes formed part of my data. It was imperative that the structure of the lesson aligned with the topic, aims and helpful in answering the research 
questions.

\section{DATA ANALYSIS AND RESULTS}

Data was analysed both quantitatively (using excel) to measure any change in performance and qualitatively focusing on solution strategies and mathematical language used in both pre-test and post-test interviews and events during the completion of assessment tasks. Firstly, I compared the performance of each learner in the pre-test and post-test. This analysis was used to establish the influence of the intervention on learners' performance in the content domain of word problems involving multiplication. I calculated the overall average performance of all learners in both pre-test and post-test. The average was calculated as a percentage. This was useful in calculating the delta. Delta is the difference from pre-test to post-test which is measured in percentage points (pp). Percentage point is the arithmetic difference of two percentages. The interview transcripts were analysed focusing on the methods that learners used to solve the problems during both pre-test and post-test. I also analysed the interview transcripts based on the change in language used by learners in the pre-test and post-test interviews. For instance, some learners started using the language of rows and columns after the intervention.

\section{Comparing performance}

The six learners wrote a pre-test at the beginning of the intervention. The aim for administering the pre-test was to get an idea of how much learners knew about solving word problems involving multiplication. Through the pretest I also hoped to gather information about the solution strategies that learners possessed to solve these kinds of problems before the intervention. The pre-test comprised the following five questions:

1. James puts cherry cupcakes in rows on a tray. Each row has 3 cherry cupcakes. James puts out 5 rows. How many cherry cupcakes does James put out?

2. Corin is putting our chairs in rows. He puts 4 chairs in each row. He has put out 4 rows. How many chairs does Carin put out?

3. Thembi is packing out counters. She puts 6 counters in a row. She makes 5 rows of counter How many counters does Thembi pack out?

4. Viren is packing books into boxes. He puts 5 books onto one box. He puts 6 books onto another box. How many books does Viren pack into the two boxes?

5. Siya is putting out rows of chairs. He puts 4 chairs in each row. There are 6 rows. How many chairs will Siya use?

The test was marked according to the following criteria:
Criteria 1: The use of symbols or icons to represent the problem

Criteria 2: The use of number sentence

Criteria 3: The use of arrays

Criteria 4: Correct answer

Figure 1 shows that out of the six learners, four learners improved their results in the post-test while two learners regressed. It is also important to note from the graph that the lowest in the pre-test scored $30 \%$ and the highest scored $85 \%$, while in the post-test the lowest scored $45 \%$ and highest scored $95 \%$. This indicates an upward shift in the overall learner performance.

In Table 1, learners are categorized into three groups based on the change in performance achieved for the two tests. The most improved learners are represented by the green bands (Learners $A$ and $B$ ), those that improved fairly are represented by the yellow bands (Learners $C$ and $E$ ), and those that regressed are represented by the red bands (Learners $D$ and $F$ ). The positive sign to the numbers in the far-right column indicate that there was an improvement in learner performance, and the negative sign to the numbers indicate that there was a regression in learner performance. Learners $A$ and $B$ were the most improved with $25 \%$ and $65 \%$ change in performance respectively. Learners $\mathrm{C}$ and $\mathrm{E}$ improved fairly with $15 \%$ and $20 \%$ change in performance respectively. Finally, Learners $D$ and $F$ regressed with a change of $-10 \%$ performance each. In my further discussion, I will focus much on learners $A$ and $B$, who are the most improved learners.

\section{Calculating the average score}

After calculating the performance of individual learners in the pre-test and post-test, I calculated the average performance of all learners presented in decimal points and percentage. This information is represented in Figure 2. The five decimal rows represent questions 1 to 5 in increasing order and C1 to C4 represent the marking criteria.

In Table 2a, the average performance of learners in the pre-test was $55 \%$, and Table $2 \mathrm{~b}$ shows that the average performance of learners in the post-test was $73 \%$. The figure also shows that while learners improved their performance more on questions 2 and 3 , there was no change on question number 1 with minor improvement on questions 3 and 4 . There was a remarkable improvement on criteria 1 (use symbols or icons) and 3 (use arrays). This implies learners were able to use symbols or icons and arrays more when solving the problems in the posttest.

I calculated the difference between pre and post-test (delta) by subtracting the average performance in pre-test from average performance in post-test. The results are presented in Table 3.

Table 3 shows that the average performance of 


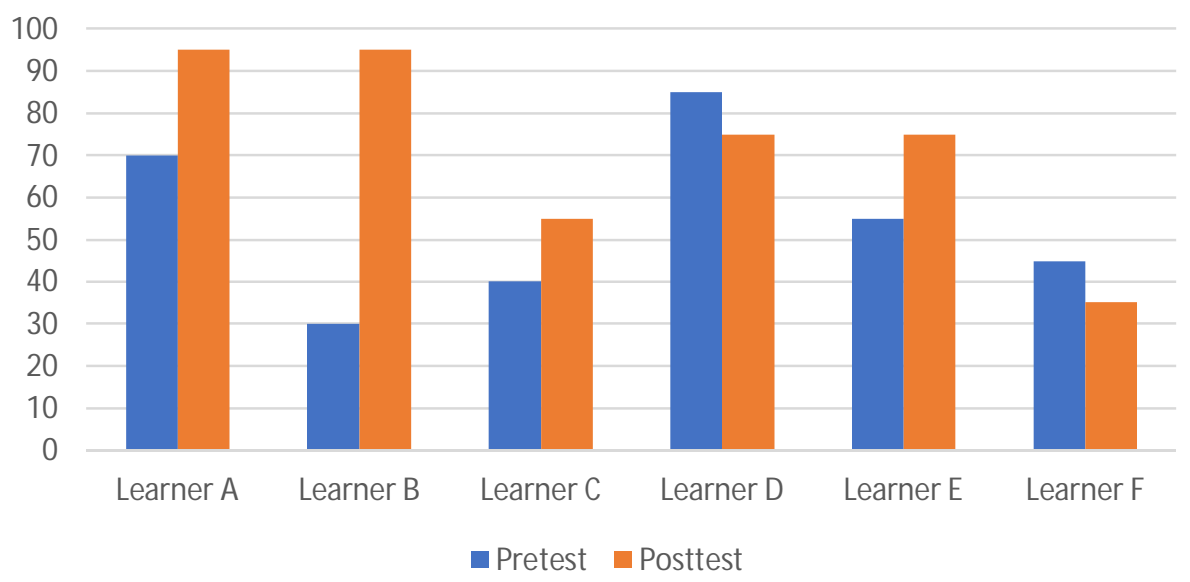

Figure 1. Learners' performance in the pre-test and post-test results.

Table 1. Learner categories based on performance change.

\begin{tabular}{cccc}
\hline Learner identity & Pre-test score (\%) & Post-test score (\%) & Delta (change) (pp) \\
\hline A & 70 & 95 & +25 \\
B & 30 & 95 & +65 \\
C & 40 & 55 & +15 \\
D & 85 & 75 & -10 \\
E & 55 & 75 & +20 \\
F & 45 & 35 & -10 \\
\hline
\end{tabular}
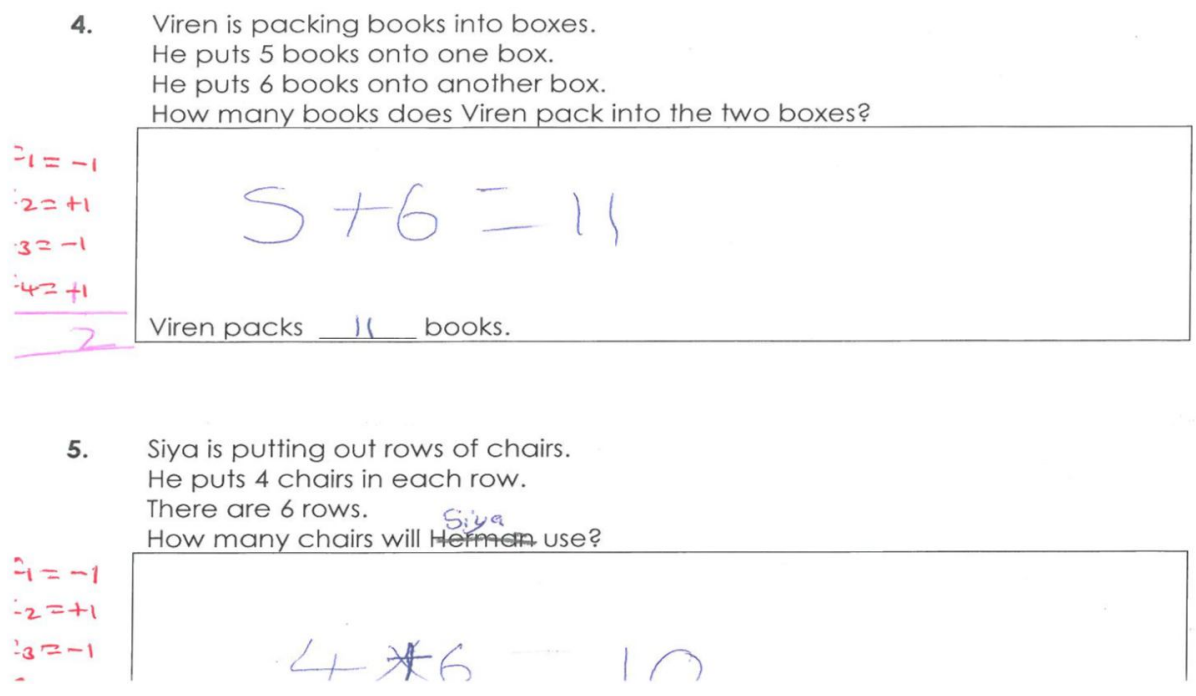

Figure 2. Learner's solution strategy before intervention.

learners increased by 18 percentage points after the intervention. This means that the intervention had a positive influence on overall learner performance. It is also evident from the table that learners' use of criteria 2 (number sentences) dropped in the post-test as depicted by the negative decimals. This means that in the posttest, learners were not writing number sentences for the problem.

\section{Learners A and B}

As discussed earlier, learners $A$ and $B$ were the most improved. Learner A scored $30 \%$ in the pretest, which is 
Table 2. Average scores.

\begin{tabular}{|c|c|c|c|c|c|c|c|c|c|}
\hline \multicolumn{5}{|c|}{ 2a: Average score (pre-test) } & \multicolumn{5}{|c|}{ 2b: Average score (post-test) } \\
\hline \multicolumn{5}{|c|}{ Average pre-test } & \multicolumn{5}{|c|}{ Average post-test } \\
\hline C1 & C2 & C3 & C4 & Score & C1 & C2 & C3 & C4 & Score \\
\hline 0.67 & 0.67 & 0.50 & 0.83 & 2.67 & 0.67 & 0.83 & 0.33 & 0.83 & 2.67 \\
\hline 0.17 & 0.83 & 0.17 & 0.83 & 2.00 & 1.00 & 0.67 & 0.83 & 1.00 & 3.50 \\
\hline 0.67 & 0.50 & 0.33 & 0.50 & 1.83 & 0.83 & 0.83 & 0.67 & 0.83 & 3.17 \\
\hline 0.33 & 0.83 & 0.33 & 0.67 & 2.17 & 0.83 & 0.67 & 0.83 & 0.50 & 2.83 \\
\hline 0.33 & 0.83 & 0.33 & 0.83 & 2.33 & 0.83 & 0.33 & 0.67 & 0.67 & 2.50 \\
\hline Average & & & & $55 \%$ & & & & & $73 \%$ \\
\hline
\end{tabular}

Table 3. Average score change in pretest and post-test (Delta).

\begin{tabular}{ccccc}
\hline C1 & C 2 & C3 & C4 & Score \\
\hline 0.00 & 0.17 & -0.17 & 0.00 & 0.00 \\
0.83 & -0.17 & 0.67 & 1.50 & 0.00 \\
0.17 & 0.33 & 0.33 & 1.33 & 1.33 \\
0.50 & -0.17 & 0.50 & 0.67 & 0.67 \\
0.50 & -0.50 & 0.33 & 0.17 & 0.17 \\
Delta & & & & $18 p p$ \\
\hline
\end{tabular}

below average, while learner B scored $70 \%$ in the pretest which is above average. However, both learners scored $95 \%$ in the post-test. Figures 2 and 3 are samples of pre-test and post-test scripts of learner A.

As shown on the pre-test script, Learner A demonstrated no understanding or knowledge of multiplicative reasoning. The learner added any numbers that he saw in the questions throughout and got an incorrect answer after adding the two numbers in the multiplication problem. This demonstrates some knowledge of additive reasoning in the learner. While in the post-test as shown on the script, the learner was able draw an array to represent the question, wrote the correct number sentence, and got the correct answer. However, the learner lost marks on question number 4 where he used multiplicative concepts instead of additive concepts. Question number 4 was important in this test because it allowed researcher to judge whether learners knew where to apply the concepts learnt. This leaves the researcher with a question about learners improved performance as to whether it is evidence of understanding of multiplicative concepts or it was a mere recall of what was done in the lesson. The learners' approach to question demonstrates lack of understanding of where to apply the multiplicative reasoning concepts and where to apply additive reasoning concepts. The learners' approach to questions, correlated to what he said in the interview after the pre-test. Figure 4 is an extract from the interview transcript.

The learner chose to explain how he approached question number 4 . In lines 52-58, in solving question number 4 the learner says, "I said $6+5$ because there was a 6 and 5". Much as this is applicable for only this question, the learner used the same solution strategy in all questions, which resulted in him scoring the lowest. This suggests limited understanding of multiplicative reasoning concepts. During the lesson, the learner engaged actively in discussions and class tasks. In the post-test, the learner used the method of drawing arrays to represent the problem. There was consistency in the use of number sentence, but this time the number sentences correctly represented the problem and led him to correct answers. The solution methods he used in the post-test also correlated with what the learner said in the post-test interview (Figure 5).

In the post-test interview lines 99-109, the learner explained that he had to draw to represent the problem in order to find the answer. He showed us how he solved the problem using both the chalkboard and the paper he used to work out the problem. I continue the discussion focusing on learner B. Using the drawing method, the learner got the question item correct. This points to some usefulness of arrays in supporting learners solve multiplication word problems.

\section{Learner B}

Compared to Learner A, Learner B was already above average in the pre-test. However, she was the second most improved learner. She scored $70 \%$ in the pre-test and $95 \%$ in the post-test. Figures 6 and 7 are Learner's pre-test and post-test scripts.

As shown on the scripts, during the pre-test learner B 
4. Viren is packing books into boxes.

He puts 5 books into one box.

He puts 6 books into another box.

How many books does viren pack into the two boxes?

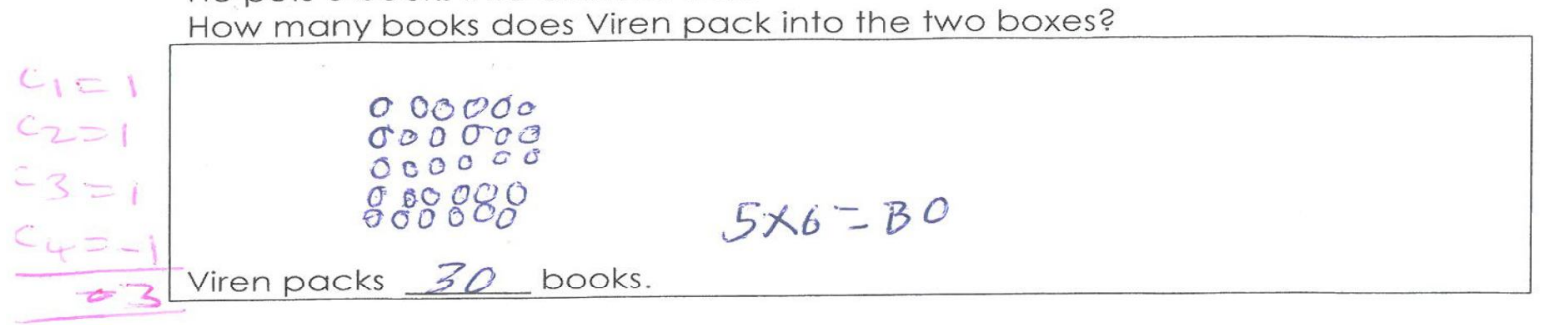

5. Siya is putting out rows of chairs.

He puts 4 chairs in each row.

There are 6 rows.

How many chairs will siya use?

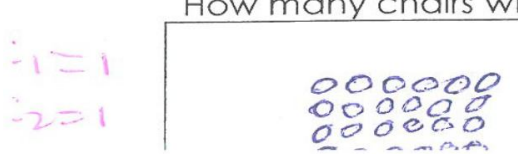

Figure 3. Learner's solution strategy after intervention.

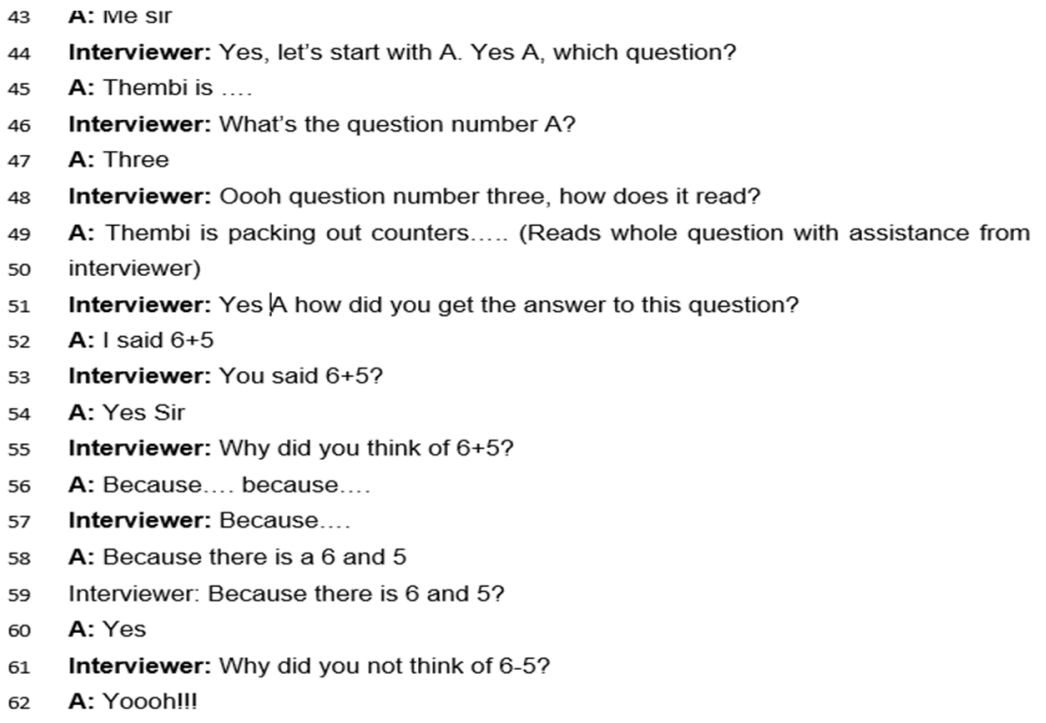

Figure 4. Interview transcript after pre-test.

demonstrated knowledge of multiplicative reasoning concepts and the use of arrays. The learner was able to draw the columns and arranged the objects in each column accordingly to form rows and columns. However, in the pre-test the learner was more skewed towards symbolic representations. As depicted on questions 1 and 2, the learner made attempts to draw real cherry cupcakes and chairs. It was a different case in the posttest where the learner drew circles and rectangles to represent cherry cupcakes and chairs respectively. Probably, this is what may have led to learner's learning gains. It is also important to note that in both tests, the learner did not use number sentences. This implies that the learner did not change in any way in criteria 2 (use of number sentences). An analysis of interview transcripts was useful in validating the learners' performance in the pre-test (Figure 8).

The learner chose to explain how she approached question 5. As shown in the transcript (lines 82-85), the learner said "I said 6 times 4 it gave me 24. I got it by counting 6,4 times like this....6, 7, 8... (learner counts to 24 while using fingers). Although it is a time-consuming method, it still led the learner to the correct answer. However, I think this demonstrates limited understanding 


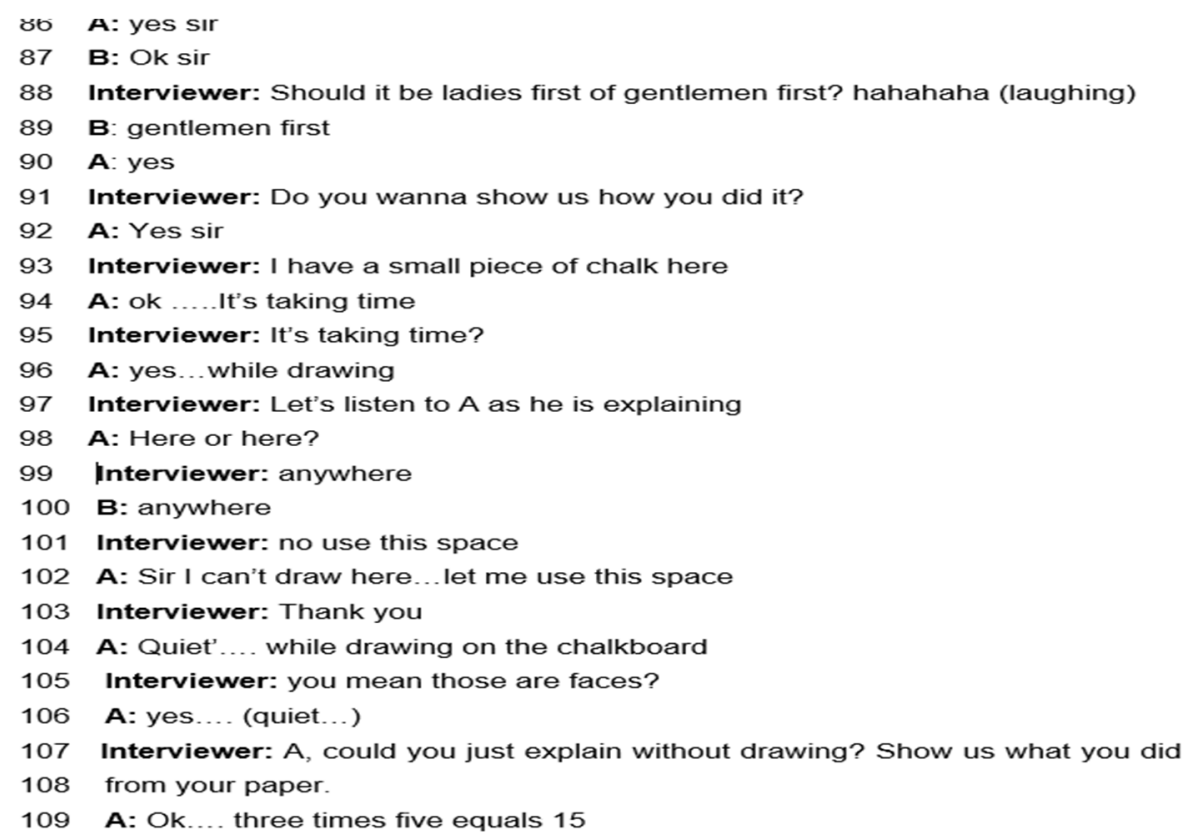

Figure 5. Interview transcript post-test.
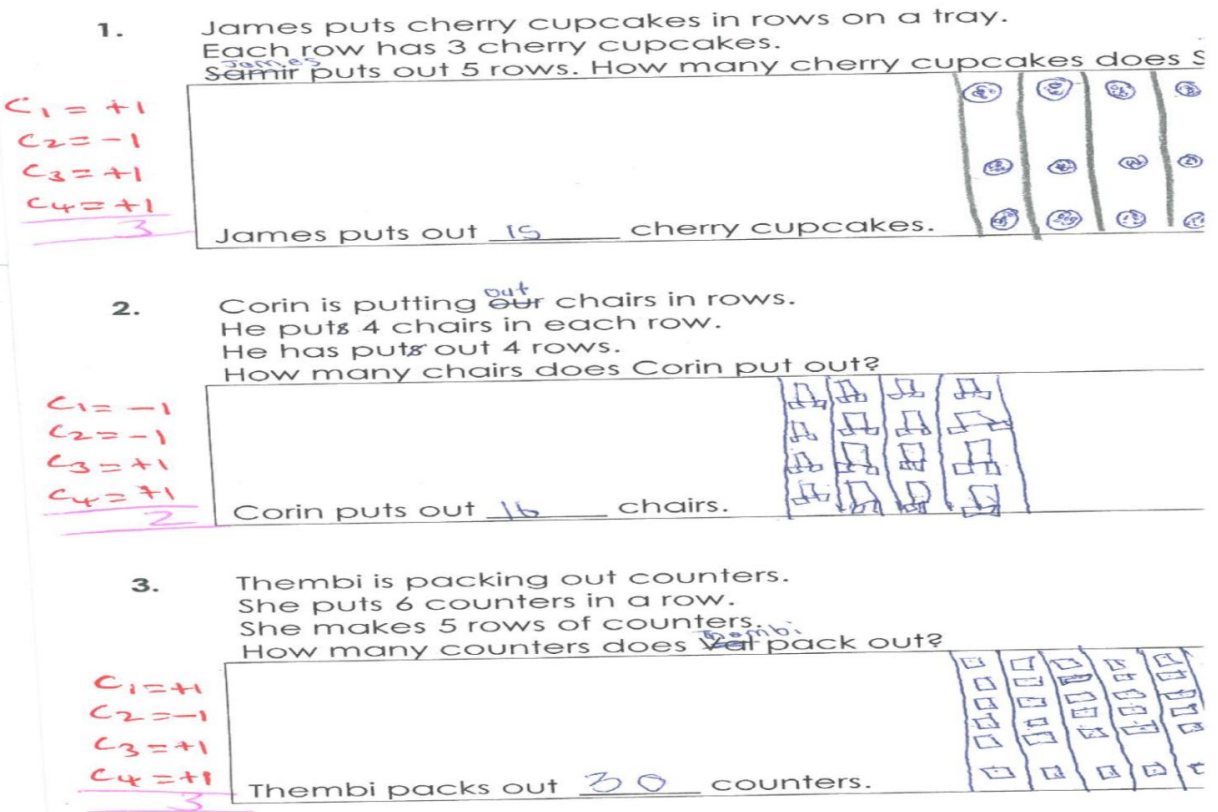

Figure 6. Pretest.

of multiplicative reasoning concepts as the learner uses additive reasoning concepts to find answers to problems that require multiplicative reasoning. During the lesson, the learner participated and did the lesson tasks. The post test interviews were helpful in giving insights about the learner's progress throughout the intervention and this is presented in Figure 9.
The post-test interview shows that there was an improvement in learner's vocabulary after the intervention. She starts using the language of rows. In lines (117-122), the learner says, "Sir I did draw five roles, and three cherry cupcakes in each row, then multiply $5 \times 3$ ". This suggests that there were some learning gains in the learner following the intervention. 
1.4 cherry cupcakes in rows on a tray. Each row has 3 cherry cupcakes. Each many cherry cupcakes does
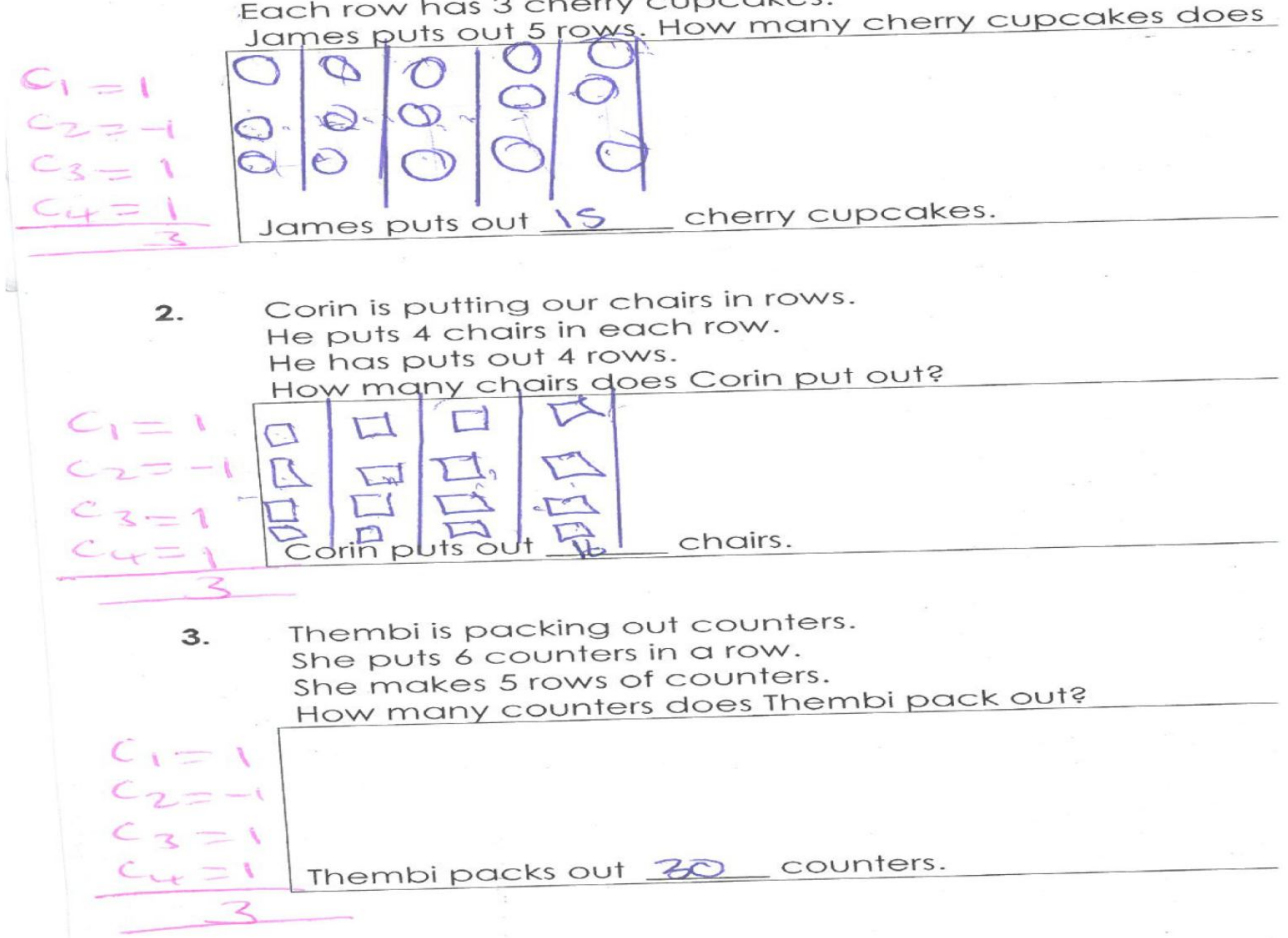

Figure 7. Post-test.

Interviewer: Is 1 too small or too big?

A: It's too small

Interviewer: Thank you A, lets now hear from B

B: Question number $5 ! ! !$

Interviewer: Question number 5? B, please tell us how you went about question 5?

B: Siya is putting out rows.... (reads the whole question)

Interviewer: Mhhhh

B: I said 6 times 4 and it gave me 24 . I got it by counting 6,4 times like this, $6,7,8 \ldots$

(Counts on up to 24)

Interviewer: Ok so you just had to count in 6, 4 times

B: Yes

Interviewer: And what answer did you get?

B: 24

Interviewer: Alright, thank you A and B. Now if you look at the questions, you did 4x6 and $\mathrm{A}$ did another one, but he had to add the numbers. My question to you $\mathrm{A}$ and $\mathrm{B}$ is, can you be able to help any of your friend struggling with mathematics word problems about multiplication, and do you feel you have the confidence to help somebody?

B: Yeah, I can, I have the confidence to teach my baby sister and cousin Interviewer: Oooh you can help your baby sister and cousin

B: Yes

Interviewer: What kind of mathematics do you teach them?

Figure 8. Interview after pre-test. 
Figure 9. Post-test interview. from your paper.

A: I had to draw first

B: Sir can I do? to point for us and....

B: Sir I did draw five rows by three equals 15 . to these questions?

B: it did sir answer the questions?

A: yes answer the questions.

Interviewer: A, could you just explain without drawing? Show us what you did

A: Ok .... three times five equals 15

Interviewer: So did you just go straight to $3 \times 5$ or you had to draw first

Interviewer: Thank you $A$... thank you $A$

Interviewer: yes B, quickly show us how you got your answer, but you can also use what you have here (pointing at the paper she did the working on) just

Interviewer: you had to draw 5 rows, and that's question number?

B: question number one, .......quiet while drawing

Interviewer: how many rows did you draw?

B: I draw five rows, and three cherry cupcakes in each, then multiply five

Interviewer: Thank you B. You remember guys we had a lesson on

Tuesday? Do you think the lesson we had helped you in any way to find answers

Interviewer: A, is there anything that we did in the lesson that helped you

Interviewer: alright...B if I may ask what is it that we did is that helped you

B: Mmhhhhhhh sir, we... we we sir

(n)

\section{DISCUSSION}

The results show that 4 learners improved in the post-test and 2 learners regressed. Of interest are learners $A$ and B who scored $30 \%$ and $70 \%$ respectively in the pre-test, but both improved to $95 \%$ in the post-test. These two learners were identified as low performers during sample selection as they fell in the lower third on the list. But after the intervention learner A's attainment improved by 65 $\mathrm{pp}$, while learner B showed an improvement of $25 \mathrm{pp}$. This is a remarkable achievement for a low performing learner. On average, there was an overall improvement in learners' performance by 18pp. This was obtained after subtracting the average performance of learners in the pre-test from their average performance in the post-test.

The interviews also revealed that learners' methods of solving problems improved meaningfully. Prior to the intervention, learners had no clear strategies of approaching the problems, consequently they got wrong answers. For instance, some learners were just adding or multiplying numbers without understanding the concepts underlying their actions. After the intervention, learners were able to justify their solution methods. For instance, some learners said they had to draw in order to find the answers. There was also a significant change in the language used by learners. The interviews before the intervention reveal low vocabulary in learners about the concept. After the intervention, learners were able to use the vocabulary of rows and columns to justify their solution methods.

\section{Conclusion}

The findings and discussion show that arrays have potential of improving learners' performance in general, and of those low performers in the mathematical concept of word problems involving multiplication. The sample involved learners in a township school who were categorised as high, middle and low performers. As 
depicted in the data, the most improved learners were those who were initially identified as low performers. The use of arrays seemed to support learners shift towards more efficiency in their solution strategies. For learner B, there was also evidence of improvement of her mathematical and topic specific vocabulary.

\section{RECOMMENDATION}

I would recommend that in the context of low performance, mathematics teachers should use arrays when teaching word problems involving multiplication to their learners. They should also introduce and acquaint learners with the concepts of rows and columns, which are the basis for multiplication. Further research should focus on engaging large samples of whole grade 4 classes in township schools to ensure that the results are more representative.

\section{REFERENCES}

Askew, M., Barmby, P., Hansa, S., Mathews, C., Morrison, S., and Ramdhany, V. (2017). Multiplicative Reasoning in the Intermediate phase: Teacher Resource Pack. University of Witwatersrand, Johannesburg.

Barmby, P., Harries, T., Higgins, S., and Suggate, J. (2009). The array representation and primary children's understanding and reasoning in multiplication. Educational Studies in Mathematics, 70(3): 217- 24.

Csikos, C., Szitanyi, J., and Kelemen, R. (2012). The effects of using drawings in developing young children's mathematical word problem solving: A design experiment with third grade Hungarian students. Educational Studies in Mathematics, 81(1): 47-65.

Harries, T., and Suggate, J. (2006). Exploring links across representations of numbers with young children. International Journal for Technology in Mathematics Education, 13(2): 53-64.
Pfannenstiel, K., Bryant, D., Bryant, B., and Porterfield, J. (2015). Cognitive strategy instruction for teaching word problems to primary level struggling students. Intervention in School and Clinic, 50(5): 291-296.

Plomp, T., and Nieveen, N. (2007) (Eds). An Introduction to Educational Design Research. Proceedings of the seminar conducted at the East China Normal University, Shanghai (PR China), November 23-26.

Thompson, I. (1999). Issues in Teaching Numeracy in Primary Schools. Open University Press, Buckingham.

Zhang, D., Ding, Y., Lee, S., and Chen, J (2017). Strategic development of multiplication problem solving: Patterns of students' strategy choices. Journal of Educational research, 110(2): 159-170.

Citation: Malola, M. (2020). The use of arrays in the learning of multiplication word problems in primary school. African Educational Research Journal, 8(2): 432-441. 